Article

\title{
Aetiology of Acute Lower Respiratory Infections among Children Under Five Years in Accra, Ghana
}

\author{
Theophilus K. Adiku ${ }^{1, *}$, Richard H. Asmah ${ }^{2}$, Onike Rodrigues ${ }^{3}$, Bamenla Goka ${ }^{3}$, \\ Evangeline Obodai ${ }^{1}$, Andrew A. Adjei ${ }^{4}$, Eric S. Donkor ${ }^{1}$ and George Armah ${ }^{5}$
}

1 Department of Microbiology, University of Ghana Medical School, Accra, Ghana; E-Mails: evaelli@gmail.com (E.O.); esampane-donkor@chs.ug.edu.gh (E.S.D.)

2 Department of Medical Laboratory Sciences, School of Allied Health Sciences, University of Ghana, Accra, Ghana; E-Mail: rhasmah@chs.edu.gh

3 Department of Child Health, University of Ghana Medical School, Accra, Ghana; E-Mails: ponike@uhas.edu.gh (O.R.); bamenla@yahoo.co.uk (B.G.)

4 Department of Pathology, University of Ghana Medical School, Accra, Ghana; E-Mail: andrewanthonyadjei@yahoo.com

5 Department of Electron Microscopy and Histopathology,

Noguchi Memorial Institute for Medical Research, University of Ghana, Accra, Ghana; E-Mail: garmah@noguchi.ug.edu.gh

* Author to whom correspondence should be addressed; E-Mail: tkeadiku20@ gmail.com; Tel.: +233-302-665-405; Fax: +233-302-663-062.

Academic Editor: Lawrence S. Young

Received: 16 July 2014 / Accepted: 14 January 2015 / Published: 26 January 2015

Abstract: The study aimed to investigate the aetiological agents and clinical presentations associated with acute lower respiratory infections (ALRI) among children under five years old at the Korle-Bu Teaching Hospital in Ghana. This was a cross-sectional study carried from February to December 2001. Nasopharyngeal aspirates and venous blood specimens obtained from 108 children with features suggestive of ALRI, were cultured and the isolated bacterial organisms were identified biochemically. Nasopharyngeal aspirates were also tested for Respiratory Syncitial Virus (RSV) antigen using a commercial kit (Becton Dickinson Directigen RSV test kit). A multiplex reverse transcription-PCR (RT-PCR) was also used to detect and characterize RSV using extracted RNA. Socio-demographic and clinical data were also obtained from the study subjects. Bronchopneumonia (55.5\%), bronchiolitis (25\%), lobar pneumonia (10.2), non-specific 
ALRI (4.6\%), TB, bronchitis and respiratory distress $(0.67 \%)$ were diagnosed. The prevalence of septicaemia was $10 \%$ and bacteria isolated were Staphylococcus aureus, Streptococcus pneumoniae and enteric bacteria, including Salmonella spp., Enterobacter spp and Klebsiella spp, were isolated. Out of the 108 cases, $18 \%$ tested positive for RSV, with two cases having RSV as the only aetiological pathogen detected. The subtyping analysis of RSV strains by a multiplex RT-PCR showed that subgroups A and B circulated in the season of analysis.

Keywords: acute respiratory infections; Respiratory Syncitial Virus; Staphylococcus aureus

\section{Introduction}

In developing countries acute respiratory infections (ARI), diarrhoeal diseases, malaria and malnutrition are major causes of death among young children [1]. It is estimated that $18 \%$ of all deaths in children less than five years old are attributable to ARI as an underlying or contributory cause, thus indicating ARI as the commonest cause of the deaths [2]. Infections of the lower respiratory tract are known to be important causes of morbidity as well as a leading reason of hospitalization in children in Africa [3].

Several agents have aetiologically been associated with severe ALRI (acute lower respiratory infections). These include viral agents, such as RSV, adenoviruses, influenza virus, human metapneumovirus and para-influenza virus [4,5]. A wide range of bacterial agents are also implicated in ARLI and include Streptococcus pneumoniae, Staphylococcus aureus, Haemophilus influenzae, Moraxella catarrhalis, Escherichia coli, Salmonella species Mycoplasma pneumoniae, and Chlamydia pneumoniae [6-8]. Respiratory syncytial virus (RSV) has been identified as causing proportionately more ALRI than the others particularly during the first year of life $[9,10]$. RSV is responsible for approximately $85 \%$ of cases of bronchiolitis and $20 \%$ of cases of childhood pneumonia $[9,10]$. A recent systematic review showed that RSV is responsible for 66,000 to 199,000 deaths annually among children less than five years old [11]. Vigorous initiatives are hence being developed for the prevention or reduction of RSV disease worldwide. These among others include the development of vaccines for both childhood and maternal immunization.

Whilst ALRI disease has been well documented in industrialized countries, the same cannot be said of developing countries. From the few population based estimates of the incidence of RSV disease in the developing world, the rate has been estimated between 540 to 1000 episodes per 1000 child years with peak infection in infants less than one year old [12]. In Africa, there are few reports on ALRI from Zambia [13], Ethiopia [14], Gambia [15], South Africa [16] and Kenya [17], and there is therefore paucity of data on RSV serotypes circulating on the continent. In Ghana, the first study on ALRI was in 1991 where clinical diagnosis was done with no laboratory-based identification and confirmation of the etiological agents [18]. In the present study, we investigated the aetiology of ALRI in children under five years of age in the Greater Accra region of Ghana. 


\section{Results}

The 108 children sampled in the study comprised 53 males and 55 females; their age range was 0-47 months, with majority of them (78/108) falling in the age group of $0-11$ months (Table 1$)$. About $8.3 \%$ had experienced similar illness in the past and $54.6 \%$ received antibiotics before admission (Table 2). Majority of the study subjects (54\%) were hospitalized for 8-14 days (Figure 1).

Table 1. Distribution of study population by age, sex, and proportion hospitalized.

\begin{tabular}{lccc}
\hline Age & Males & Females & Proportion Hospitalized \\
\hline 0-2 months & 14 & 15 & 26.9 \\
3-5 months & 12 & 13 & 23.1 \\
6-11 months & 12 & 12 & 22.2 \\
12-23 months & 9 & 7 & 14.8 \\
24-35 months & 6 & 5 & 10.2 \\
36-47 months & 0 & 3 & 2.8 \\
48-59 months & 0 & 0 & 0 \\
\hline
\end{tabular}

Table 2. Demographic data of children with acute lower respiratory infections.

\begin{tabular}{lll}
\hline Factor & Details & Percentage \\
\hline Past illness and immunity & Similar illness in the past & 8.3 \\
& Exclusive breast feeding up to 6 months & 86.1 \\
Subject's association with other & Siblings with same illness & 17.9 \\
children & Child attends day-care center & 9.3 \\
& Child sleeps alone & 4.7 \\
Subject's household factor & Single parents & 7.5 \\
& Median (range) no. of people in the room & $5(2-9)$ \\
& Passive smoking in the household & 20.6 \\
Self-medication (prior to admission) & Antibiotics & 54.6 \\
& Antimalarials & 56.1 \\
& Cough mixture & 41.7 \\
& Herbal medicine & 8.3 \\
& Paracetamol & 78.9 \\
\hline
\end{tabular}

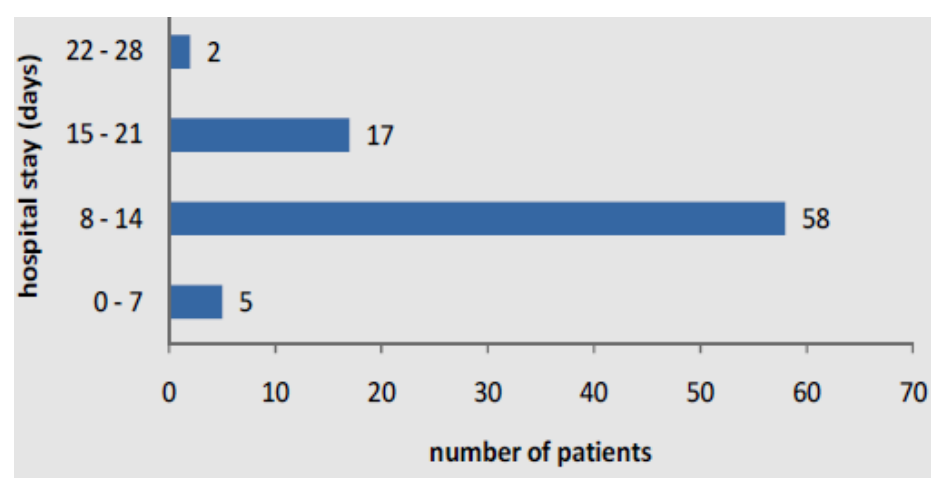

Figure 1. Duration of stay in hospital of children with acute lower respiratory infections. 
Overall, eight fatal outcomes were reported and were associated with several clinical diagnosis including meningitis, septicaemia, HIV infection and gastroenteritis. The overall prevalence of RSV infection amongst ALRI patients was 18\%. The most frequent symptoms were cough (95.4\%), difficulty in breathing $(89.8 \%)$, fever $(83.3 \%)$ and diarrhea (25.9\%) (Table 3). The most frequent causes of hospitalization of RSV patients were bronchopneumonia, bronchiolitis, pneumonia and respiratory distress (Figure 2). Generally, there were no significant differences in clinical characteristics between children who had RSV infection and other those who had other ALRI. The monthly distribution of ALRI and RSV cases are reported in Figure 3. ALRI cases occurred non-uniformly throughout the 11 months study (February to December) and peaked in July at 23 cases. RSV cases peaked in February and March (nine cases) after which it declined with no reported cases from May.

Based on bacterial culture results (Table 4), $10 \%$ of the children had evidence of septicemia and the implicated bacterial agents were Staphylococcus aureus, Streptococcus pneumoniae and a number of enteric bacteria including Salmonella spp., Enterobacter spp and Klebsiella spp. There were six cases $(5.6 \%)$ of septicaemia and ALRI/RSV infection. Culture of throat swabs and nasopharyngeal specimens yielded a wide range of organisms (Table 4), most of which are consistent with their occurrence as normal flora at these anatomical sites. The most prevalent bacterial organism isolated from the throat was Staphylococcus aureus (8\%), followed by Streptococcus pyogenes (5\%), viridians streptococci (4\%) and Candida spp. (4\%). The most prevalent bacteria isolated from the nasopharynx was Staphylococcus aureus (16\%) but enteric organisms including Enterobacter spp (6\%), Klebsiella spp. (4\%) and Escherichia coli (4\%) were also common at this anatomical site (Table 4). Nineteen samples (18.4\%) were positive on the RSV Becton-Dickenson Rapid test. Viral RNA was extracted from eight of the positive samples and multiplex PCR analysis showed that two samples were RSV group A and two were RSV group B (Figure 4).

Table 3. Clinical presentation of children with acute lower respiratory infections.

\begin{tabular}{llc}
\hline Indication & Details & \% of patients $(\mathbf{n}=\mathbf{1 0 5})$ \\
\hline Symptoms & & \\
& Cough & 95.4 \\
& Difficulty in breathing & 89.8 \\
& Wheezing & 15 \\
& Stridor & 0.9 \\
& Nasal discharge & 62.0 \\
& Difficulty in feeling & 53.3 \\
& Fever & 83.3 \\
& Diarrhoae & 25.0 \\
Mental disposition & & \\
& Normal & 68.2 \\
& Irritable & 20.6 \\
& Lethargic/drowsy & 9.3 \\
& Unconscious & 1.9 \\
\hline
\end{tabular}


Table 3. Cont.

\begin{tabular}{llc}
\hline Indication & Details & \% of patients $(\mathbf{n}=\mathbf{1 0 5})$ \\
\hline Chest signs & & \\
& Chest indraw & 44.9 \\
& Bronchial breathing & 14.2 \\
& Ronchi & 17 \\
& Crepitations & 69.8 \\
& Chest splinting & 0 \\
& Grunting & 12.3 \\
Therapy options & & \\
& Bronchodilators & 10.3 \\
& Oxygen & 51.4 \\
& Antibiotics & 96.3 \\
\hline
\end{tabular}

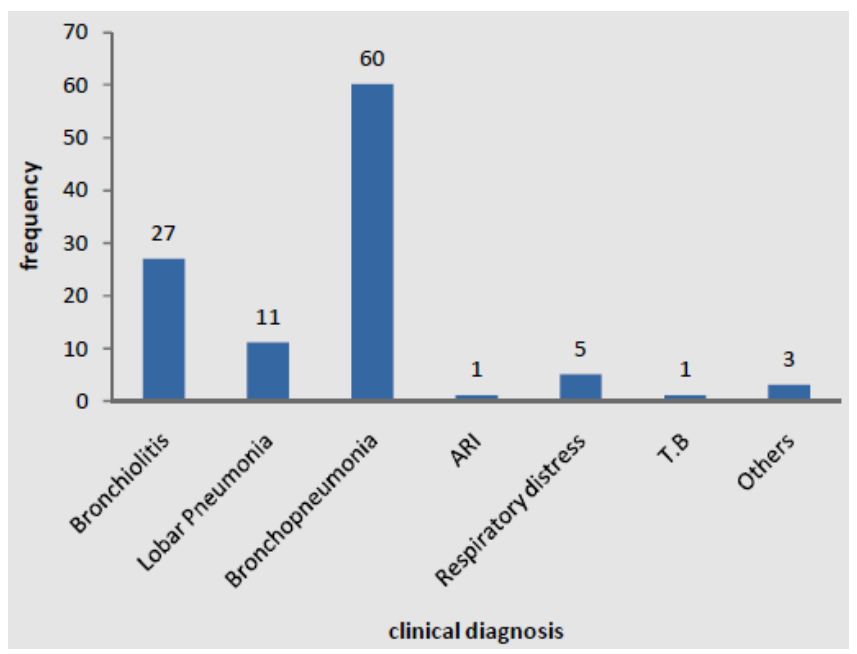

Figure 2. Clinical diagnosis of children with acute lower respiratory infections.

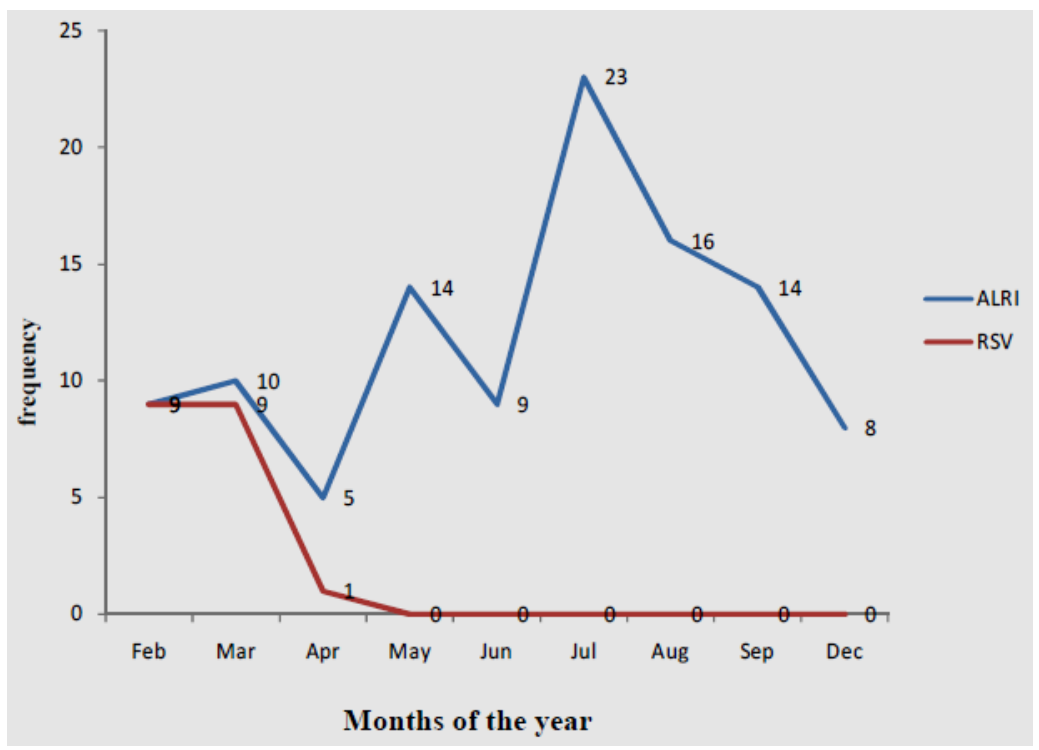

Figure 3. Monthly distribution of cases of acute lower respiratory infections and Respiratory Syncytial Virus. 
Table 4. Bacteria isolated from blood, throat swabs and nasopharyngeal specimens.

\begin{tabular}{lccc}
\hline & \multicolumn{3}{c}{ Specimen } \\
\cline { 2 - 4 } Bacteria & Blood & Throat sp & Naso sp \\
\hline Staphylococcus aureus & 4 & 8 & 16 \\
Streptococcus pneumoniae & 1 & 1 & 3 \\
Salmonella spp & 3 & 0 & 0 \\
Enterobacter spp & 1 & 1 & 6 \\
Klebsiella spp & 1 & 2 & 4 \\
Streptococcus pyogenes & 0 & 5 & 0 \\
Moraxella catarrhalis & 0 & 1 & 3 \\
Viridans streptococci & 0 & 4 & 2 \\
Pseudomonas aeuroginosa & 0 & 0 & 3 \\
Escherichia coli & 0 & 0 & 4 \\
Proteus spp. & 0 & 0 & 1 \\
\hline
\end{tabular}

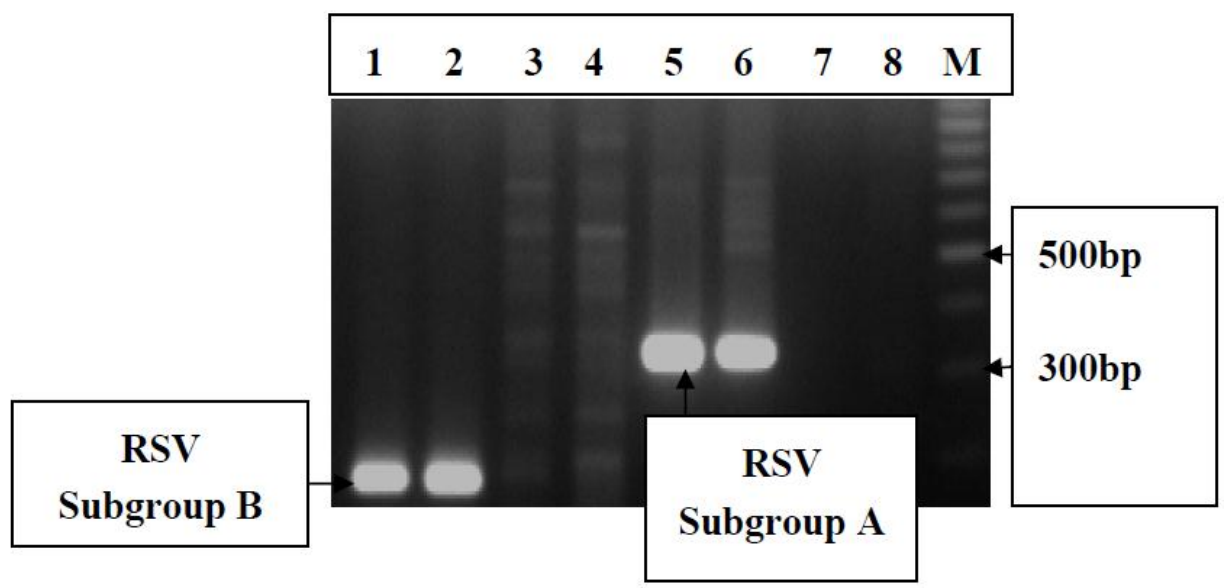

Figure 4. Electrophoregram showing type specific identification of Respiratory Syncitial Virus (RSV) groups from nasopharyngeal aspirates. Lane M is a 100 bp DNA molecular weight marker. Lanes 1 and 2, RSV group B (183 bp); lanes 5 and 6, RSV group A (334 bp); and lane 7 negative control using cDNA from rotavirus positive sample and lane 8 , negative control.

\section{Discussion}

We found that prevalence of ALRIs due to RSV infection in children observed in the present study was $18 \%$, which is relatively higher than the prevalence rates reported in several developing countries such as The Gambia, Zambia and Eithopia [13-15]. It is interesting to note that while ALRI cases appeared to occur throughout the year, RSV cases were confined to the early part of the year. This highlights the importance and role of other aetiological agents of ALRI among the study subjects, apart from RSV. Though we isolated a wide range of bacterial agents from the study subjects, the spectrum of ALRI aetiology may be more extensive, including parasites and viruses that we did not screen for. Bronchopneumonia and bronchiolitis were the most severe complications associated with ALRI infections, which concurs with previous studies [19,20]. The symptoms of ALRI infection are similar 
to those of several bacterial infections and also malaria. This may explain why prior to visiting the study hospital, majority of the study patients had been on antibiotics or antimalarial agents. Discussions with physicians who took care of the patients also showed that all RSV infections received antibiotics while on admission. This depicts RSV infection as a leading cause of prescription for antibiotics and antibiotic misuse.

All but eight patients recovered resulting in a $7.4 \%$ mortality rate, which is higher than rates reported in several countries [21]. The high rates of morbidity of RSV infection observed in the current study can have a large unfavorable impact on public health. For example, majority of the patients spent more than a week on hospital admission, which can be a major burden on the hospital facilities, such as bed turnover, staff, and high expenditure on maintaining patients per day. This can also be stressful on the families involved, as parents have to absent themselves from work and home, placing strain on the financial resources of the family. The high case fatality observed in this study requires serious attention in the light of achievement of Millennium Development Goal (MDG) 4, which is to reduce child mortality by two-thirds.

S. aureus, which was the most common bacterial organism in the nasopharyngeal aspirate samples, is known to occur as a normal flora in the nasopharynx of most healthy children. Consequently, its occurrence in septicemia among the children may be indicative of endogenous sources of infection. However, molecular studies are needed to confirm this. Our data shows that $S$. aureus may be an important cause of septicaemia among children in Ghana. The absence of organisms like Haemophilus influenzae and Neisseria meningitidis in nasopharyngeal aspirates is surprising as these organisms are normal residents in the nasopharynx. Haemophilus influenzae and Neisseria meningitides are fastidious organisms, and the culture method used may not have been sensitive enough to detect them.

The multiplex-PCR assay was able to detect and confirmed the presence of RSV and thus useful in assessing the contribution of RSV to the overall burden of respiratory illness in the community and can be of use in diagnostic settings where subtype information might be sought. Both group A and B RSV were found to co-circulate during the study period. The results from this study will enhance the clinical management of ALRI as well as provide information for evaluating any future vaccines; especially for RSV.

There are a few limitations of the study. Firstly, our ALRI surveillance did not cover a full year and cases in January may have been missed resulting in an under-estimation of RSV prevalence. Secondly, the small volume of blood used for the cultures may have resulted in low sensitivity of detection of bacterial organisms in the blood. Additionally, nasopharyngeal aspirates may not be very useful for diagnosis of ALRI due to bacteria and isolates from blood does not necessarily imply causation of ALRI. Thirdly, only the RSV positive rapid antigen tests were tested by PCR for subgrouping due to scarcity of resources. The PCR test in general is more sensitive than the rapid antigen test, and thus additional cases could have been identified if the PCR method was used to evaluate all the samples. Our data on RSV subgrouping is limited and we recommend further studies using a larger sample size to determine RSV subgroups in the country. 


\section{Methods}

The methodology for the study was based on the WHO generic protocol to examine the incidence of lower respiratory infection due to RSV in children less than 5 years old [22]. Standard protocols and control strains were employed in the laboratory investigations.

\subsection{Study Site and Population}

This was a cross-sectional study carried out at the Department of Child Health at the Korle-Bu Teaching Hospital located in Accra, Ghana. The Korle-Bu Teaching Hospital is the major referral Hospital in Ghana with a daily outpatient attendance of more than 1000. Prospectively, one hundred and eight (108) children were recruited consecutively into this study from February to December 2001. This included all children under 5 years old with ALRI who sought medical assistance at the department of Child Health. All the ALRI cases in the study were community acquired and there were no secondary referrals from other hospitals. All the study children had received the Haemophilus influenzae Type $\mathrm{b}$ vaccine but none of them had received pneumococcal vaccination. The bio-data of the study subjects recruited into the study were obtained by administering a questionnaire. Risk factors, such as malnutrition, overcrowding, and passive smoking, were recorded. Known asthmatics and children with abnormal cardiovascular systems were not recruited in the study. ALRI was defined according to the age of the subject as follows. For children $<2$ months, breathing rate of 60 per minute or severe chest in-drawing or stridor or wheezing or apnea. For children 2-11 months, breathing rate of 50 per minute or chest in-drawing or stridor or wheezing or apnea. Finally, for children 12-59 months, breathing rate of 40 per minute or chest in-drawing or stridor or wheezing or apnea. The admitting physician managed all children recruited into the study according to the standard departmental protocol for ALRI.

The study was approved by the Ethical and Protocol Review Committee of the University of Ghana Medical School and written informed consent of the parents or the caregiver of children was obtained before sample collection.

\subsection{Sample Collection}

Nasopharyngeal aspirates, throat swabs and blood samples were collected from the study children after they were diagnosed of ALRI. Nasopharyngeal aspirates and throat swabs were collected from all the children while venous blood samples were collected from one hundred and four of them who were fit for bleeding. Nasopharyngeal aspirates were obtained using the sterile single-use Argyle ${ }^{\circledR}$ Deele Suction catheter with mucus trap kit. Initially, nasopharyngeal aspirates were collected by aspiration through a catheter and then washed down into the attached tube with $2 \mathrm{~mL}$ sterile saline solution as transport medium. The various types of samples collected were transported on ice to the Microbiology Laboratory of the University of Ghana Medical School located in Accra, the capital city of Ghana. A rapid diagnostic test to detect RSV was carried out on nasopharyngeal aspirates using the Becton-Dickenson RSV Kit (recommended by WHO). Nasopharyngeal aspirates, throat swabs and blood samples were cultured for isolation and identification of bacteria. Details of the laboratory investigation are described as follows: 


\subsection{Culture and Identification of Bacterial Isolates}

Blood samples were inoculated into tryptone soy and thioglycolate broths, and then subcultured onto sheep blood agar and chocolate agar $[23,24]$. Throat swab and nasopharyngeal specimens were cultured on sheep blood agar and enriched chocolate agar [23,24]. Bacterial isolates obtained from the cultures were identified based on colonial morphology Gram staining and a battery of biochemical reactions [19-22]. Streptococcus pneumoniae and viridian streptococci were differentiated by Optochin sensitivity [19]. Staphylococcus aureus was identified by Coagulase test [23]. Haemophilus spp. and Moraxella catarrhalis were identified using an in vitro diagnostic system (Becton Dickinson, Franklin Lakes, NJ, USA) according to the manufacturer's recommendations. Streptococcus pyogenes was identified by Bacitracin susceptibility. Gram negative rods were identified by Analytical Profile Index.

\subsection{RSV Becton-Dickenson Rapid Test}

RSV was identified from fresh aspirates using the WHO recommended Becton-Dickenson Rapid RSV diagnostic kit according to the manufacturer's recommendations. All positive samples were analyzed by PCR for confirmation of antigen positivity as well as the differentiation of serotypes.

\subsection{RSV Viral RNA Extraction, Reverse Transcription (RT) Reaction and Multiplex PCR Analysis}

Viral RNA was extracted from RSV using RNaid extraction kit (Q BIO gene, UK). The extraction process was done following the manufacturer's instruction. The RNA extracted samples were stored at $-20{ }^{\circ} \mathrm{C}$. The purified ssRNA was reversed transcribed as described by Stockton et al. [25] with slight modifications. Briefly, $1 \mu \mathrm{L}$ of hexamer random primers (20 mU; PdN6; Pharmacia Biotech) was added to $22.2 \mu \mathrm{L}$ ssRNA template. To this was added $17.8 \mu \mathrm{L}$ of master mix. The master mix comprised $3.5 \mu \mathrm{L} 5 \mathrm{X}$ Go buffer (Promega, USA), 10U avian myeloblastosis (AMV) reverse transcriptase (Promega, USA), $1 \mu \mathrm{L} 10 \mathrm{mM}$, dTTP, $1 \mu \mathrm{L} 10 \mathrm{mM}$ dATP, $1 \mu \mathrm{L} 10 \mathrm{mM}$ dCTP, $1 \mu \mathrm{L}$ $10 \mathrm{mM} \mathrm{dGTP}$ and $8.1 \mu \mathrm{L}$ RNase free water. The mixture was incubated at room temperature for $10 \mathrm{~min}$ at $42{ }^{\circ} \mathrm{C}$ in a Perkin Elmer GenAmp 2700 PCR Machine (Applied Biosystems, Middletown, CT, USA) for $45 \mathrm{~min}$ and $95{ }^{\circ} \mathrm{C}$ for $5 \mathrm{~min}$ to inactivate the AMV enzyme. Two negative controls were set up using $22.2 \mu \mathrm{L}$ of RNA sample known to be positive for rotavirus and nuclease free water. The cDNA products generated was stored at $-20{ }^{\circ} \mathrm{C}$.

The $\mathrm{N}$ and $\mathrm{P}$ regions of the RSV genome were amplified using a forward primer (RSV AB F) and a reverse primer (RSV AB R). The primers described by Stockton et al., [25] were used in the PCR analysis. Briefly, the slightly modified PCR reaction mix of $50 \mu \mathrm{L}$ contained $5 \mathrm{X}$ Go PCR buffer (Promega, Madison, WI, USA), $200 \mu \mathrm{M}$ of each of the 4 oligonucleotide triphospates (dNTPs) (Promega, USA), 5 pmols of each primer, 1.6 U RNasin (Promega, USA) and 1.5 units of Taq Polymerase enzyme (Promega, USA). Ten microliters of cDNA product from the RT reaction was used as template for the amplification reaction. Nuclease free water was used to make up the volume to $50 \mu \mathrm{L}$. The reaction mix was spun down for $30 \mathrm{~s}$ at 14,000 rpm and the amplification was carried out using a Primus 25 Advance PCR machine (PEQLAB, GmbH, Erlangen, Germany). The cycling parameters for the 1 st round PCR with the primers were as follows: $94{ }^{\circ} \mathrm{C}$ for $2 \mathrm{~min}$, followed by 35 cycles of $94{ }^{\circ} \mathrm{C}$ for $1 \mathrm{~min}, 50{ }^{\circ} \mathrm{C}$ for $1 \mathrm{~min}, 72{ }^{\circ} \mathrm{C}$ for $1 \mathrm{~min}$. For each reaction, a positive control (RSV 
positive sample) and a negative control (no DNA template added) were run. In the second round multiplex PCR, $1 \mu \mathrm{L}$ of first round PCR product, 25 pmols of forward and reverse primers for subtyping were used. The other parameters above remained the same. The PCR cycling parameters were as follows: $94{ }^{\circ} \mathrm{C}$ for $2 \mathrm{~min}$, followed by 35 cycles of $94{ }^{\circ} \mathrm{C}$ for min, $60{ }^{\circ} \mathrm{C}$ for $30 \mathrm{~s}, 72{ }^{\circ} \mathrm{C}$ for 1 min. Primers for the identification of RSV subtypes A and B were used. On completion of the PCR, the products were electrophoresed on a $2 \%$ agarose gel and stained with $0.5 \mu \mathrm{g} / \mathrm{mL}$ ethidium bromide to detect the presence of amplified DNA fragments. Ten microliters of each sample was added to $2 \mu \mathrm{L}$ of bromophenol (5X) gel loading dye for the electrophoresis. Hundred base pair DNA molecular weight marker (Promega, USA) was run alongside the PCR products. The gel was prepared and electrophoresed in $1 \mathrm{X}$ TAE buffer using a mini gel system at 100 volts for one hour and the gel photographed over a UV transilluminator.

\subsection{Analysis of Data}

All data were double entered and stored on a microcomputer. Analysis of the generated data was carried out using EPI Info Version 16 software (CDC, Atlanta, GA, USA). The strategies taken to analyze the data involved descriptive statistics, including geometric means, frequencies, ranges and prevalence rates of the study variables. Significant differences, associations and interrelationships of the variables were also assessed at a level of $p<0.05$.

\section{Conclusions}

The study concludes that ALRI has an annual distribution in Accra, and peaks around the middle of the year (July). RSV accounts for a significant proportion of the ALRI and RSV cases appear to be highly seasonal, occurring in the early part of the year. Apart from RSV, several other microbial agents are involved in ALRI in Accra, and a more targeted epidemiological study of these causative organisms is required.

\section{Acknowledgments}

The authors wish to thank the pediatricians and nurses of the Child Health Department of the Korle $\mathrm{Bu}$ Teaching Hospital for their assistance during sample collection and the staff of the Virology and Electron, Histopathology Departments of Noguchi Memorial Institute where the molecular work was done. In addition we would like to thank Isaac Boamah and Gloria Asala of the Department of Microbiology, University of Ghana Medical School, Korle-Bu for their technical assistance during the work.

\section{Author Contributions}

T.K.A., G.A., R.H.A. and O.R. were involved in the conception and design of study. E.O., T.K.A., R.H.A. and A.A.A. undertook laboratory analysis. T.K.A., R.H.A., E.S.D. and E.O. carried out data analysis. R.H.A., E.S.D. and T.K.A. drafted the manuscript. All authors gave final approval of the version to be published. 


\section{Conflicts of Interest}

The authors declare no conflict of interest.

\section{References}

1. Bryce, J.; Boschi-Pinto, C.; Shibuya, K.; Black, R.E. WHO estimates of the causes of death in children. Lancet 2005, 365, 1147-1152.

2. World Health Organization. Burden of Disease Project; World Health Organization: Geneva, Switzerland, 2005.

3. Singh, V.; Aneja, S. Pneumonia-Management in the Developing World. Paediatr. Respir. Rev. 2011, 12, 52-59.

4. Fiore, A.E.; Shay, D.K.; Broder, K.; Iskander, J.K.; Uyeki, T.M.; Mootrey, G.; Bresee, J.S.; Cox, N.J.; Centers for Disease Control and Prevention. Prevention and control of seasonal influenza with vaccines: Recommendations of the Advisory Committee on Immunization Practices (ACIP), 2009. MMWR Recomm. Rep. 2009, 58, 1-52.

5. Stensballe, L.G.; Devasundaram, J.K.; Simoes, E.A. Respiratory syncytial virus epidemics: The ups and downs of a seasonal virus. Pediatr. Infect. Dis. J. 2003, 22, 21-32.

6. Ranganathan, S.C.; Sonnappa, S. Pneumoniae and other respiratory infections. Pediatr. Clin. North Am. 2009, 56, 135-156.

7. Chisti, M.J.; Tebruegge, M.; La Vincente, S.; Graham, S.M.; Duke, T. Pneumonia in severely malnourished children in developing countries-Mortality risk, aetiology and validity of WHO clinical signs: A systematic review. Trop. Med. Int. Health 2009, 14, 1173-1189.

8. Atkinson, M.; Yanney, M.; Stephenson, T.; Smyth, A. Effective treatment strategies for paediatric community-acquired pneumonia. Expert Opin. Pharmacother. 2007, 8, 1091-10101.

9. Mulholland, E.K.; Simoes, E.A.; Costales, M.O.; McGrath, E.J.; Manalac, E.M.; Gove, S. Standardized diagnosis of pneumonia in developing countries. Pediatr. Infect. Dis. J. 1992, 11, 77-81.

10. Shann, F.; Gratten, M.; Germer, S.; Linnemann, V.; Hazlett, D.; Payne, R. Aetiology of Pneumonia in Children in Goroka Hospital, Papua New Guinea. Lancet 1984, 2, 537-541.

11. Nair, H.; Nokes, D.J.; Gessner, B.D.; Dherani, M.; Madhi, S.A.; Singleton, R.J.; O’Brien, K.L.; Roca, A.; Wright, P.F.; Bruce, N.; et al. Global burden of acute lower respiratory infections due to respiratory syncytial virus in young children: A systematic review and meta-analysis. Lancet 2010, 375, 1545-1555.

12. Mulholland, K. The problem of assessing global disease burden: The example of acute respiratory infections. In Report of the Technical Review Group Meeting, 7-8 June 1998; World Health Organization: Geneva, Switzerland, 2000; who/vrd/gen/98.02.

13. Saijo, M.; Terunuma, H.; Mizuta, K.; Mpabalumui, E.M.; Mouze, M.; Oshitani, H.; Luo, N.; Suzuki, H.; Numazaki, Y. Respiratory syncytial virus in children with acute respiratory infections in Zambia. Epid. Infect. 1998, 121, 397-400. 
14. Muhe, L.; Tilahun, W.; Lulseged, S.; Kebede, S.; Enaro, D.; Ringgertz, S.; Krovall, G.; Gove, S.; Mulhollard, E.K. Etiology of pneumonia, sepis, and meningitis in infants younger than 3 month of age in Ethiopia. Paediatr. Infect. Dis. J. 1999, 11, S56-S61.

15. Weber, M.W.; Milligan, P.; Hilton, S.; Lahai, G.; Whittle, H.; Mulholland, E.K.; Greenwood, B.M. Risk factors for severe respiratory syncytial virus infection leading to hospital admission in children in the Western Region of The Gambia. Int. J. Epidermiol. 1999, 28, 157-162.

16. Vardas, E.; Blaavw, D.; McAnerney, J. The epidermiology of respiratory syncytial virus (RSV) infections in South African children. South Afr. Med. J. 1999, 89, 1079-1084.

17. Okiro, E.A.; Ngama, M.; Bett, A.; Nokes, D.J. The Incidence and Clinical Burden of Respiratory Syncytial Virus Disease Identified through Hospital Outpatient Presentations in Kenyan Children. PLoS One 2012, 7, e52520.

18. Afari, E.A.; Hiroyuki, S.; Nakano, T.; Binka, F.; Assoku, A.; Amaning, K.; Mensah, G.; Fenteng, J. Acute Respiratory Infections in Children under five in Two Rural Communities in Southern Ghana. Jpn. J. Trop. Med. Hyg. 1991, 19, 275-280.

19. Moore, H.; Burgner, D.; Carville, K.; Jacoby, P.; Richmond, P.; Lehmann, D. Diverging trends for lower respiratory infections in non-Aboriginal and Aboriginal children. J. Paediatr. Child Health 2007, 43, 451-457.

20. Peck, A.J.; Holman, R.C.; Curns, A.T.; Lingappa, J.R.; Cheek, J.E.; Singleton, R.J.; Carver, K.; Anderson, L.J. Lower respiratory tract infections among American Indian and Alaska Native children and the general population of U.S. children. Pediatr. Infect. Dis. J. 2005, 24, 342-351.

21. Welliver R.C., Sr.; Checchia, P.A.; Bauman, J.H.; Fernandes, A.W.; Mahadevia, P.J.; Hall, C.B. Fatality rates in published reports of RSV hospitalizations among high-risk and otherwise healthy children. Curr. Med. Res. Opin. 2010, 26, 2175-2181.

22. Wright, P.F.; Cutts, F.T. (2000) Generic Protocol to examine the incidence of lower respiratory infection due to respiratory syncytial virus in children less than 5 years of age. WHO/V\&B/00.08.

23. Baron, J.E.; Peterson, L.R.; Finegold, S.M. Bailey and Scott Diagnostic Microbiology, 9th ed.; C.V. Mosby Co.: St. Louis, MO, USA.

24. Flournoy, D.J.; Wongpradit, S.; Silberg, S.L. Facilitating Identification of Lactose-Fermenting Enterobacteriaceae on MacConkey Agar. Proc. Okla. Acad. Sci. 1990, 70, 5-8.

25. Stockton, J.; Ellis, J.S.; Saville, M.; Clewley, J.P.; Zambon, M.C. Multiplex PCR for typing and subtyping influenza and respiratory syncytial viruses. J. Clin. Microbiol. 1998, 36, 2990-2995.

(C) 2015 by the authors; licensee MDPI, Basel, Switzerland. This article is an open access article distributed under the terms and conditions of the Creative Commons Attribution license (http://creativecommons.org/licenses/by/4.0/). 